\title{
JENDELA HEMAT ENERGI PADA FASADE RUMAH SUSUN DI JAKARTA
}

\author{
Daryanto; Firza Utama S. \\ Architecture Department, Faculty of Engineering, Binus University \\ Jln. K.H. Syahdan No. 9, Palmerah, Jakarta Barat 11480 \\ daryanto@binus.edu; firza.utama@binus.ac.id
}

\begin{abstract}
Window is one of building components that is directly related to lighting and ventilation. Currently a lot of vertical housings pay less attention to the design of energy-efficient windows. This study aims to find energy efficient windows that are applicable to vertical housing. Surveys on some vertical housings in Jakarta was conducted and environmental simulation programs using CFD and Ecotect was used to explore and analyze the performance of windows for natural lighting and ventilation and further developing of energy efficient windows. The result showed that the Jalousie windows mounted on the center of wall facing out and two louvers above the entrance and upperside of walls in the opposite side of rooms, combined with openings at the bottom of doors are able to create optimum cross ventilation. The resulted wind speed within the range of 0.15 to $0.12 \mathrm{~m} / \mathrm{s}$ is enough to make comfortable air flow effect, and the average natural lighting of 200 lux is adequate for residential activity.
\end{abstract}

Keywords: vertical housing, energy- saving window, lighting, ventilation

\begin{abstract}
ABSTRAK
Jendela merupakan salah satu komponen bangunan yang berhubungan langsung dengan aspek pencahayaan dan penghawaan. Dalam kondisi sekarang banyak rumah susun kurang memperhatikan rancangan jendela hemat energi. Penelitian ini bertujuan untuk menemukan jendela hemat energi untuk Rumah Susun. Kajian pada beberapa jendela Rusun di Jakarta dan Simulasi program CFD (computational Fluid Dynamics)serta Ecotech digunakan untuk menggali, menganalisis serta mengembangkan kinerja jendela untuk memperoleh penghawaan dan pencahayaan alami yang memanfaatkan potensi iklim secara optimal. Hasil penelitian menunjukkan bahwa jendela nako pada bagian tengah dinding yang menghadap keluar dan dua kisikisi di atas pintu masuk dan di atas dinding ruangan yang berseberangan yang dikombinasikan dengan rongga di bagian bawah pintu mampu menggerakkan ventilasi silang di area hunian. Kecepatan angin yang dihasilkan pada kisaran 0,15 sampai 1,2 $\mathrm{m} / \mathrm{s}$ cukup untuk memperoleh efek sejuk dan penerangan alami rata-rata 200 lux layak untuk penerangan aktivitas hunian.
\end{abstract}

Kata kunci: rumah susun, jendela hemat energi, pencahayaan, penghawaan 


\section{PENDAHULUAN}

Pertambahan penduduk di kota-kota besar terus meningkat, sementara keterbatasan lahan yang ada mengarah kepada fasilitas hunian masal yang disusun secara vertikal (Aswito, 2004). Kebijakan dan rencana strategis pembangunan rumah susun di kawasan perkotaan tahun 2007-2011 menyebutkan bahwa berdasarkan hasil Survei Sosial Ekonomi Nasional 2004 Badan Pusat Statistik (BPS), menyebutkan bahwa terdapat 55 juta keluarga dari jumlah penduduk Indonesia sebesar 217,1 juta jiwa. Sebanyak 5,9 juta keluarga belum memiliki rumah. Sementara setiap tahun terjadi penambahan kebutuhan rumah akibat penambahan keluarga baru rata-rata sekitar 820.000 unit rumah (www.kemenpera.go.id/).

Jendela menjadi masalah pada rumah susun, masih kurang memperhatikan kenyamanan termal dan visual terkait kondisi iklim tropis yang panas dan lembab (Daryanto, 2007). Dari pengamatan yang telah dilakukan, banyak penghuni yang merasa kurang nyaman termal dan mempergunakan system pengkondisian buatan (AC) sehingga akan berdampak terhadap energi yang dikonsumsi.Hal ini tentu kurang sesuai dengan tujuan semula dalam membangun rumah susun yang dihuni oleh masyarakat berpenghasilan menengah kebawah, sehingga desain harus dibuat dengan mempertimbangkan aspek penghematan energi.Rumah susun merupakan kelompok gedung bertingkat tinggi dengan kecepatan angin dan cahaya alami perlu pengendalian secara khusus. Sedangkan salah satu kunci penting dalam penghematan energi pada gedung bertingkat tinggi adalah sistim kenyamanan termal akibat radiasi matahari dan pengendalian angin melalui rancangan aktif dan pasif (Karyono, 2004). Untuk mengatasi masalah kenyamanan termal dan visual ini, umumnya masyarakat penghuni rumah susun melengkapinya dengan sistem pengkondisian buatan, sedangkan AC mengkonsumsi energi listrik yang cukup besar.

Rendahnya daya beli masyarakat untuk mendapatkan hunian yang layak merupakan kendala utama dalam pemanfaatan energi alternatif dalam rumah susun, sehingga penghematan energi merupakan upaya yang harus dilakukan dalam mengurangi konsumsi energi. Rencana dibangunnya 1000 tower rumah susun di Indonesia akan berdampak terhadap peningkatan kebutuhan energi listrik yang sangat besar. Oleh karena itu penghematan energi dalam perancangan jendela pada Rumah Susun perlu memperoleh perhatian sangat serius.

Penghematan energi melalui perancangan bangunan mengarah pada aspek penghawaan buatan dan penerangan ruang, maupun peralatan listrik rumah tangga. Pada bangunan perumahan, porsi terbesar dari penggunaan energi adalah pengendalian faktor iklim, sehingga kualitas kenyamanan termal dan visual menjadi pertimbangan utama (Daryanto,2007). Arsitektur sadar energi memadukan antara kebutuhan dan kenyamanan dalam tatanan arsitektur yang baik sehingga mempunyai nilai tambah yang diharapkan. Selubung bangunan mempunyai peran penting dalam penghematan energy untuk antisipasi perambatan panas dan pemanfaatan cahaya alami untuk penerangan ruang (Priatman, 2007).

Agar bangunan dapat berperan dengan baik sebagai pengendali lingkungan, berdasarkan penelitian yang dilakukan oleh Ken Yeang dalam bukunya The Green Skyscraper (Yeang, 1999) terdapat beberapa parameter yang menjadi konsep dasar desain sadar energy, di antaranya: (1) kenyamanan termal - bangunan harus dapat mengontrol perolehan sinar matahari sesuai dengan kebutuhannya. Jika berada pada iklim dingin, bangunan harus mampu menerima radiasi matahari yang cukup untuk pemanasan, sedangkan untuk bengunan yang berada pada iklim panas, harus mampu mencegah radiasi matahari secukupnya untuk pendinginan; (2) kenyamanan visual - bangunan harus mampu mengontrol perolehan cahaya matahari sesuai dengan keperluannya; (3) pengendalian lingkungan pasif - kontrol dilakukan untuk mencapai kenyamanan termal maupun visual dengan memanfaatkan seluruh potensi iklim setempat yang dikendalikan dengan elemen-elemen bangunan 
(atap, dinding, lantai, pintu, jendela, aksesori, lansekap) yang dirancang tanpa menggunakan energy listrik; (4) pengendalian lingkungan aktif - kontrol dilakukan untuk mencapai kenyamanan termal dan visual dengan memanfaatkan potensi iklim yang ada dan dirancang dengan bantuan teknologi maupun instrument yang mengggunakan energi listrik; (5) pengendalian lingkungan hybrid untuk mencapai kenyamanan termal mauoun visual dengan kombinasi pasif dan aktif untuk memperoleh kinerja bangunan yang maksimal.

Aplikasi dalam kasus bangunan rumah susun, kondominium 28 lantai hemat energi pada Idaman Residence, Kuala Lumpur, Malaysia: (1) memberikan penekanan terhadap elemen penghijauan didalam dan disekeliling bangunan; (2) menyediakan banyak bukaan, ruang tangga dan lobby lift yang menggunakan ventilasi alami, ventilasi silang dan pencahayaan alami; (3) menggunakan tabir matahari pada fasade dan pada bagian bukaan lainnya, agar suhu tidak terlalu panas pada waktu sore; (4) pemasangan lansekap pada belkon, teras; (5) pemanfaatan air daur ulang hujan untuk menjaga udara relatif nyaman; (6) jendela-jendela diposisikan untuk memaksimalkan ventilasi silang, cahaya siang, dan pemandangan; (7) sistem spray mist (semprot kabut pada roof top untuk mendinginkan dan membersihkan udara.

Aplikasi konsep hemat enrgi pada SYMHOUSE, Kolkata, India, arsitek: Piercy Conner Architects, bangunan apartment 5 lapis berkonsep rumah sustainable yang menggunakan bahan-bahan yang mudah didaur ulang.

SymHouse merupakan rumah susun yang dibangun gengan material pabrikasi dan menggunakan tenaga ahli lokal untuk mengurangi biaya pembangunan. Material bangunan yang digunakan adalah rangka baja dengan plat beton prefab. Material baja memang mempunyai energy content yang tinggi, tapi tingkat recycleability-nya tinggi. Rusun yang berada pada iklim panas lembab ini memiliki rasio jendela yang fleksible sesuai dengan kebutuhan kenyamanan pada musim panas dan dingin.Selubung bangunan berupa tirai besi lipat perforasi, dirancang dengan iklim setempat. Terdapat sepuluh tipe desain tirai berbeda menurun analisis lintasan matahari setempat yang menjamin penetrasi penerangan alami dan sirkulasi alami ke semua ruang dalam. Pada bagian atap terdapat taman yang berfungsi untuk menjaga kelembaban dan kebersihan udara.

\section{METODE}

Penelitian ini dilakukan di Jakarta, dengan melakukan pengamatan dan pengukuran lapangan dan perhitungan model simulasi. Pengamatan lapangan pada tiga rusun: Kemayoran, Benhil dan Petamburan, untuk dianalisis dari aspek kenyamanan termal dan visual. Pengamatan dilakukan dengan mengukur temperatur luar dan dalam bangunan, kelembaban, aliran angin dan kuat cahaya alami, mengukur lebar, panjang dan tinggi ruang, orientasi ruang dan luas jendela. Alat ukur yang digunakan adalah: Thermometer, Hygrometer, Anemometer, Hot wire Anemometer dan Luxmeter, dilakukan untuk mendapatkan gambaran prediksi sejauh mana kondisi temperatur, kelembaban, kecepatan angin di dalam unit rusun selama setahun.Pengukuran dilakukan pada beberapa Rusun sampel selama tiga minggu, pada dua unit hunian di lantai tiga dan empat, untuk dipetakan dan dianalisis. Simulasi mempergunakan bantuan program computer CFD dan Ecotech, dengan kondisi ruang yang dijadikan sebagai model, yaitu ruang unit RuSun dengan ukuran 4 x 3 tinggi 2,7 mirip kondisi lapangan unut rusun Kemayoran.

Hasil pengukuran lapangan, berupa temperatur rata-rata luar dan dalam, yang dianggap mewakili bulan pengamatan tersebut. Hasil pengamatan lapangan hanya menunjukkan data selama tiga minggu. Pengukuran tersebut tidak dapat memprediksi temperatur selama setahun.Untuk memprediksi temperatur luar dan dalam selama setahun perlu dilakukan dengan simulasi. Program 
komputer Ecotech akan menghitung temperatur/jam dalam setahun baik untuk aliran angin dan cahaya alami yang masuk ke dalam ruang.

Hasil pengukuran lapangan pada bulan tertentu menjadi masukan bagi perhitungan dengan simulasi. Dari kedua data tersebut dapat dianalisis pengaruh termal dan cahaya tersebut terhadap kenyamanan ruang, sehinggga akan dapat disimpulkan, bahwa jenis jendela mana dari kedua variabel tersebut yang mempunyai pengaruh panas yang lebih sedikit dari jendela lainnya. Analisis dari datadata tersebut banyak berupa grafik-grafik, yang memudahkan untuk membandingkan antara variabel yang satu dengan yang lainnya.

Hasil penelitian adalah rekomendasi untuk membangun model jendela yang dapat dipergunakan sebagai jendela rumah susun sesuai dengan iklim di Jakarta. Model jendela yang dikembangkan dari hasil penelitian ini dipergunalan untuk simulasi CFD, guna mengetahui prediksi aliran udara dan intensitas cahaya di dalam unit rumah susun.Hasil tersebut dianalisis berdasarkan kriteria-kriteria yang dibuat untuk menyaring potensi dan masalah dari masing-masing variabel.

\section{HASIL DAN PEMBAHASAN}

\section{Posisi dan Bidang Bukaan}

Dari hasil evaluasi desain jendela pada Rumah Susun yang telah diobservasi, luasnya rata-rata telah mencukupi berkisar 20\%, sedangkan untuk fungsi mengalirkan udara. Maka dari itu, sistem bukaan yang terbaik adalah jendela kaca nako, karena dapat ditutup dan dibuka semaksimal mungkin. Peletakan jendela yang baik adalah posisi di tengah sisi fasade untuk udara masuk dan perlu ditambahkan lubang ventilasi pada dinding seberang, yang dimaksudkan agar aliran udara dan masuknya cahaya dapat masuk seoptimal mungkin. Bukaan jendela kaca nako memiliki kelebihan dalam pengaturan aliran udara sesuai dengan kodisi yang dikehendaki penghuni dan mudah dalam perawatan.Sedang untuk jendela kaca nako pada lantai dasar perlu ditambahkan factor keamanan. Dari ketiga tipe rumah susun, denah Rusun Kemayoran lebih mudah mengalirkan angin sehingga struktur bangunan menjadi lebih sejuk, yang kemudian berpengaruh terhadap temperatur di dalam ruang.

\section{Material Jendela}

Dari segi kualitas, material jendela kosen kayu yang dipergunakan oleh rusun Petamburan dan Benhil memiliki daya tahan kurang lama untuk digunakan pada gedung bertingkat di daerah tropis lembab meskipun dari segi harga lebih murah dibandingkan dengan material kosen aluminium pada rumah susun Kemayoran. Bahan aluminium harganya relatif mahal, tapi jika dibuat secara masal dan untuk kepentingan dalam jangka panjang akan relatif murah.

\section{Pelindung Jendela (Tritisan)}

Untuk mengurangi penetrasi panas matahari, jendela perlu pelindung (tritisan), yang menghadap ke timur dan barat, menggunakan pelindung horizontal, sedangkan untuk yang menghadap ke utara dan selatan menggunakan pelindung vertikal. Di samping melidungi radiasi matahari, tritisan juga bergungsi untuk melindungi jendela dari pengaruh hujan.

\section{Orientasi Bangunan}

Orientasi bangunan rumah susun yang memanjang kearah timur- ke barat lebih sedikit menerima pengaruh panas pada fasade jika dibandingkan dengan bangunan yang berorientasi utara 
selatan. Unit hunian Rusun berderet tanpa rongga seperti pada Rusun Petamburan dan Benhil mengalirkan udara kurang maksimal. Hal ini terlihat dari hasil pengukuran lapangan yang memperlihatkan hasil pengukuran aliran angin yang berpengaruh terhadap suhu lebih sejuk.

\section{Temuan Hasil Survei}

Tabel 1 di bawah ini memuat hasil temuan dari survei yang dilakukan di Rumah Susun Bendungan Hilir.

Tabel 1

Temuan dari Survei di Rumah Susun Bendungan Hilir

\begin{tabular}{ll}
\hline Luas unit kamar & $24 \mathrm{~m} 2$ \\
\hline Luas \& letak jendela & cukup (20\% dari luas lantai) \\
\hline Material & $\begin{array}{l}\text { daun jendela tolak kaca bening dengan kosen dan rangka kayu, letaknya di tengah } \\
\text { dengan pelindung tritisan, cahaya alami merata, perawatan kaca sisi luar yang } \\
\text { berdebu mengganggu kebersihan jendela dan masuknya cahaya alami }\end{array}$ \\
\hline Desain tata ruang & $\begin{array}{l}\text { sederhana, yang memudahkan masuk cahaya alami dan sirkulasi udara cukup baik } \\
\text { area sirkulasi cukup luas untuk sosialisasi (double loaded corridor). terdapat } \\
\text { penyekat ruang/furnitur yang mengganggu sirkulasi udara alami dan cahaya alami }\end{array}$ \\
\hline Suasana lingkungan & $\begin{array}{l}\text { banyak pohon rindang sehingga suasana tidak terlalu panas, jendela yang terhalang } \\
\text { pohon, unit ruang hunian kurang memperoleh cahaya alami. Penempatan area service } \\
\text { ( dapur dan kamar mandi) diletakkan sejajar dengan zona unit hunian, sehingga } \\
\text { mempermudah perawatan. Area lorong yang relative cukup lebar sangat bermanfaat } \\
\text { bagi penghuni untuk sosialisasi, khususnya pada siang hari, penerangan alami cukup } \\
\text { terang dan sirkulasi udara mengalir dengan baik }\end{array}$ \\
\hline Pemeliharaan gedung & secara menyeluruh kurang dikelola dengan baik \\
\hline
\end{tabular}

Tabel 2 di bawah ini memuat perbandingan hasil pengukuran lapangan dari kondisi jendela

Tabel 2

Hasil Pengukuran Intensitas Cahaya Alami, Aliran Udara dan Kelembaban

\begin{tabular}{|c|c|c|c|}
\hline & Cahaya & Suhu & Kelembaban \\
\hline Rusun Petamburan & $\begin{array}{l}\text { Cukup baik, pengaruh } \\
\text { penyekat ruang ruang yang } \\
\text { menghambat masuknya } \\
\text { cahaya ( } 100 \text { lux) }\end{array}$ & $\begin{array}{l}\text { Relative tinggi, karena } \\
\text { pengaruh desain bukaan } \\
\text { jendela tolak, blok } \\
\text { bangunan dan memanjang } \\
\text { (29-34)oC }\end{array}$ & $\begin{array}{l}\text { Relatif tinggi, bukaan } \\
\text { jendela tidak bisa optimal } \\
(>60 \%)\end{array}$ \\
\hline Rusun Kemayoran & $\begin{array}{lrr}\text { Luas jendela } & \text { dan } \\
\text { perletakkannya, } & \text { tanpa } \\
\text { adanya penyekat, } & \text { cahaya } \\
\text { alami lebih } & \text { lelasa } \\
\text { menerangi ruang. } & \text { ( } 200 \\
\text { lux) } & \end{array}$ & $\begin{array}{l}\text { Penataan ruang } \text { dan } \\
\text { kondisi lingkungan dan } \\
\text { luas serta letak jendela, } \\
\text { berakibat suhu cukup } \\
\text { sejuk (27-30)oC }\end{array}$ & $\begin{array}{ll}\text { Aliran } & \text { angin dan } \\
\text { penghilauan, } & \text { berdampak } \\
\text { terhadap } & \text { kelembaban } \\
\text { antara }(40-60) \% & \end{array}$ \\
\hline Rusun Bendungan Hilir & $\begin{array}{l}\text { Posisi jendela ditengah } \\
\text { dari dua sisi, cahaya alami } \\
\text { masuk cukup baik, namun } \\
\text { untuk daerah servis kurang } \\
\text { terang.(180 lux) }\end{array}$ & $\begin{array}{l}\text { Kondisi udara didalam } \\
\text { ruangan berkisar } 30 \text { o C, } \\
\text { yang diakibatkan oleh } \\
\text { terhambatnya aliran udara } \\
\text { diantara dua sisi jendela } \\
\text { tolak. }\end{array}$ & $\begin{array}{l}\text { Kelembaban } \\
\text { berkisar }>60 \% \text {, adara } \\
\text { desain bukaan jendela } \\
\text { tolak yang tidak bisa } \\
\text { terbuka secara maksimal }\end{array}$ \\
\hline
\end{tabular}


Dari studi banding hasil evaluasi terhadap ketiga Rumah Susun, Rumah Susun Kemayoran adalah model yang dipilih untuk melakukan eksperimen dengan model jendela nako, tolak jungkit poros horizontal dan jendela putar-poros vertical, menggunakan simulasi Ecotect \&Winair. Gambar 1 adalah model yang dibuat, dan Gambar 2 adalah simulasi pergerakan udaranya.

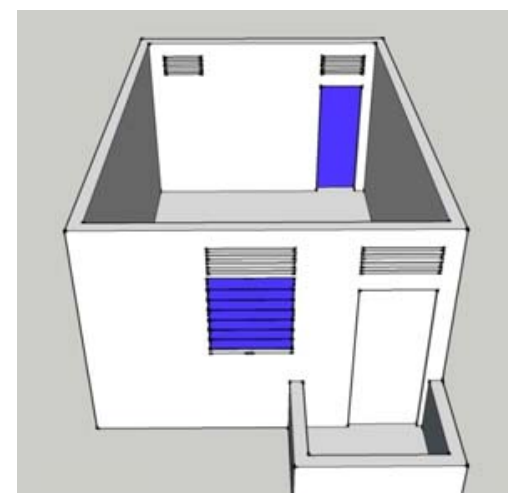

Gambar 1. Model ruang dengan perletakan posisi jendela yang ideal. Pergerakan udara pada model Jendela Nako dengan posisi ditengah ruang dan penggunaan 2 jalusi pada samping kiri dan kanan.

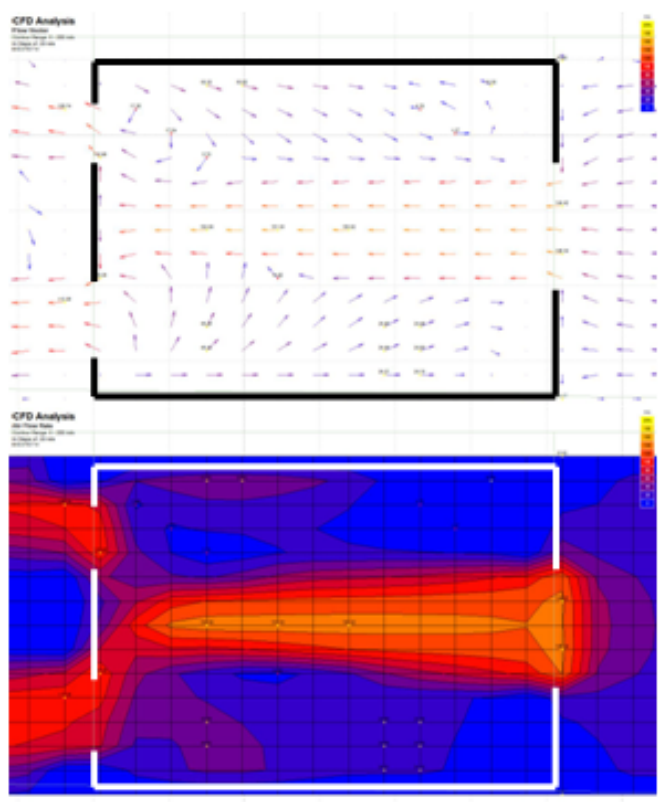

Gambar 2. Simulasi pergerakan udara pada model Jendela Nako dengan posisi ditengah ruang dan penggunaan 2 jalusi pada samping kiri dan kanan (Atas: Flow Vector, Bawah: Air Flow Rate).

\section{PENUTUP}

\section{Kesimpulan}

Jendela sebagai salah satu komponen dari selubung bangunan mempunyai peran penting dalam mengendalikan energi terkait sistem pencahayaan dan penghawaan. Beberapa kriteria yang perlu diperhatikan dalam merancang jendela antara lain: luas bidang bukaan (jendela kaca), posisi atau letaknya pada fasade, perlunya bidang pelindung/tritisan, flexibilitas bukaan untuk memberikan aliran udara dapat diatur sesuai kebutuhan, serta material kerangka kosen.

Aluminium atau UPVC merupakan material yang baik untuk kosen pada jendela rumah susun. Walaupun harga relatif mahal, masa penggunaannya bisa ratusan tahun. Mengingat kondisi di Indonesia beriklim tropis lembab, pemilihan material jendela pada bangunan bertingkat perlu dipertimbangkan keawetannya. Dengan pembuatan secara massal, penekanan harga kosen aluminium atau UPVC dapat menjadi argumentasi dipilihnya material tersebut.

Semakin besar kebutuhan rumah susun mengakibatkan meningkatnya permintaan energi listrik yang sangat besar (18 \%/tahun), sedangkan perencanaan pemerintah untuk peningkatan kebutuhan listrik hanya 13\%/tahun. Sehingga pada suatu saat biaya pengadaan listrik akan menjadi mahal, karena kebutuhan listrik semakin besar dan pemerintah tidak akan sanggup lagi mensubsidi, 
apa lagi dengan menipisnya cadangan minyak bumi dan Indonesia menjadi pengimpor minyak. Melihat kenyataan tersebut sudah saatnya seluruh komponen bangsa untuk memikirkan konservasi energi dengan pendekatan multidisiplin di era globalisasi. Hanya bangsa dan negara yang memikirkan dan mengusahakan konservasi energi yang akan dapat survive dalam berkompetisi di era global. Kriteria hemat energi merupakan tantangan bagi para arsitek/perancang bangunan untuk berimprovisasi dalam mewujudkan karya arsitektur yang inovatif. Pengembangan model jendela alternatif yang hemat energi perlu dilanjutkan. Mengingat persediaan energi yang cenderung menipis, konsep hemat energi perlu menjadi kriteria penting dalam perancangan rumah susun pada khusunya dan seluruh gedung pada umumnya. Bangunan yang tidak tanggap terhadap energi pada saatnya akan ditinggalkan karena bangunan akan terlalu mahal untuk digunakan.

\section{Saran}

Sudah waktunya arsitek memikirkan rancangan rumah susun yang hemat energi, tidak hanya dari aspek jendela dengan desain pasif, tapi juga dari desain model jendela aktif dan dari aspek bangunan lainnya.Teknis pemecahan rancangan bangunan hemat energi di Indonesia berbeda dengan dengan kawasan subtropis. Hal ini penting untuk disadari oleh para arsitek agar dalam mengadopsi bentuk dari konsep rancangan arsitektur dari negeri barat (yang umumnya beriklim subtropis) tidak terjebak pada kekliruan yang mendasar.

Hal ini dapat dilihat dari ukuran dan bentuk yang seragam pada semua sisi bangunan, sedangkan pada setiap sisi bangunan menerima intensitas dan radiasi sinar matahari yang berbedabeda. Melalui kajian pada jendela pada rumah susun yang ada dan simulasi model jendela, penelitian ini diharapkan dapat menghasilkan model jendela yang hemat energi, dalam hal ini akan dihasilkan bentuk dan ukuran terbaik secara spesifik pada sisi bangunan dan posisinya dalam ketinggian bangunan. Model yang dihasilkan dari penelitian ini kemudian dapat digunakan sebagai acuan bagi banyak pihak dalam merancang jendela dan tabir matahari pada rumah susun di Indonesia.

\section{DAFTAR PUSTAKA}

Daryanto. (2007). Konsep selubung ganda pada rumah susun hemat energy. Lokakarya III, Pengembangan Teknologi Hemat Energi pada Rumah Susun di Indonesia, Unika Parahyangan- Bandung.

Karyono, T. H. (31 Oktober 2004). Bangunan hemat energi: rancangan pasif dan aktif. Jakarta: Kompas.

Priatman, Jimmy. (2007). Perancangan selubung bangunan yang hemat energy. Dimensi, 19.

Yeang, Ken (1999). The Green Skyscrapers: Toward a Vertical Theory of Urban Design for Asian Cities. Kuala Lumpur: T.R hamzah \& Yeang Sdn Bhd. 